\title{
UV-VIS SPECTROELECTROCHEMICAL IN SITU STUDY DURING THE ELECTROSYNTHESIS OF COPOLYMERS
}

\author{
M. A. DEL VALLE ${ }^{1}$, A. MOTHEO ${ }^{2}$ AND A. M. R. RAMÍREZ ${ }^{3, *}$ \\ ${ }^{1}$ Pontificia Universidad Católica de Chile, Laboratorio de Electroquímica de Polímeros, Av. V. Mackenna 4860, 7820436, Macul, \\ Santiago, Chile. \\ ${ }^{2}$ Universidade de São Paulo, Instituto de Química de São Carlos, P.O. Box 780, CEP 13560-970, São Carlos, SP, Brasil. \\ ${ }^{3}$ Universidad Mayor, Núcleo Química y Bioquímica, Facultad de Estudios Interdisciplinarios, Laboratorio de Electroquímica, Av. \\ Alemania 0281, 4801043-Temuco, Chile.
}

\begin{abstract}
In this work, the synthesis of poly(aniline-co-o-methoxyaniline) is performed using purely electrochemical techniques, coupled to UV-vis spectroscopy in situ, in 3D. The electrocopolymerization is carried out on ITO electrodes, in various monomer ratios aniline/o-methoxyaniline varying between 0.1 to 0.4 mol $\mathrm{L}^{-1}$ in $\mathrm{H}_{2} \mathrm{SO}_{4}$ $1.0 \mathrm{~mol} \mathrm{~L}^{-1}$. The homo- and copolymers were characterized by cyclic voltammetry, in situ UV-Visible, and scanning electron microscopy. The results show the important information provided by UV-Visible spectroscopy coupled with electrochemical techniques. Thus, it is observed that the reactivity that gives the $o$-methoxy group in the aniline ring, damages the conductivity of the polymer, due to the occlusion of oligomers of $\mathrm{N}$-phenyl-1,4-benzoquinonediimine and/or with the structure of oxazine. On the other hand, the SEM images show morphological changes associated with the progress of the synthesis, which can be related with the less conductivity produced by $o$-methoxy, despite the greater reactivity.
\end{abstract}

Keywords: Electropolymerization; spectro-electrochemical; polyaniline; poly-o-methoxyaniline, poly(aniline-co-o-methoxyaniline).

\section{INTRODUCTION}

Conducting polymers (CPs) have been studied in recent past decades, due to their different and important applications in various areas. One of the most interesting $\mathrm{CP}$ is polyaniline (PANI) which has been synthesized via chemical [1] or electrochemical methods, using different supporting electrolytes and working electrodes, among them steel, platinum, FTO ITO, etc. [2-7]. In addition, the aniline derivatives have presented interesting results in corrosion protection $[9,10]$, photovoltaic cells [11], among others.

Poly-o-methoxyaniline (POMA) is one of the derivatives, which has attracted considerable attention, because it maintains characteristics similar to those of PANI, but with a more compact morphology. An interesting possibility would be to prepare copolymer with aniline, generating poly(aniline-co-omethoxyaniline), with a block-type conformation [5] and an intermediate conductivity to that of both homopolymers [8].

Currently there are various characterization techniques generally used postsynthesis. One of the most interesting tools in the characterization of polymers is the spectroscopy in the UV-Vis region, because it gives an idea of the compounds present $[12,13]$. This interesting technique has been coupled to electrochemicals methods, giving the possibility to in-situ information. Thereby, in literature there are much information about spectro-electrochemistry studies, in relation to the formation of homo- and copolymers from derivatives, such as diphenylamine or $o$-phenylenediamine [14], describing the influence of the position of the substituents on the benzene ring in the formation of oligomers. In addition, there are currently several studies available on spectro-electrochemical studies of polymers derived from PANI, which present two-dimensional graphics [15], however, they do not provide a cleaner and more complete visual image of what is produced during polymer electrosynthesis, as Zimmermann et al. does with $p$ amino-diphenylamine [16].

In this way and considering the properties of poly(aniline-co-omethoxyaniline), it is proposed here to perform a spectro-electrochemical study, SE, thinking about the possibility of observing the potential region where polymer formation and/or the generation of oligomers occurs, to establish the influence on these reactions of the methoxy group in the ortho position of aniline, complementing with subsequent morphological characterization by electron scanning microscopy, SEM.

\section{EXPERIMENTAL}

The electrolyte solutions were prepared with distilled $99.5 \%$ aniline + bidistilled $o$-methoxyaniline (Aldrich) and $99.5 \% \mathrm{H}_{2} \mathrm{SO}_{4}$ (J.T. Baker).
They were constituted by monomer in concentration that varies between 0.1 and $0.4 \mathrm{~mol} \mathrm{~L}^{-1}$ in proportions aniline/o-methoxyaniline (ANI: OMA) $1: 0 ; 3$ : $1 ; 1: 1 ; 1: 3$ and $0: 1+1.0 \mathrm{~mol} \mathrm{~L}^{-1} \mathrm{H}_{2} \mathrm{SO}_{4}$ as supporting electrolyte. Milli-Q water is used to prepare all the solutions and for cleaning the materials. All the experiments were performed at $25 \pm 2{ }^{\circ} \mathrm{C}$.

The SE studies were carried out in a spectro-electrochemical cell corresponding to a conventional quartz cell from Shimadzu, $10 \mathrm{~mm}$ path length, volume $3.5 \mathrm{~mL}$ with PTFE lid, using two platinum electrodes $\left(10 \cdot 0.5 \mathrm{~cm}^{2}\right)$ as a counter-electrode, which were placed perpendicular to the optical passage, to free the passage of light and generate a homogeneous electric field on the surface of a conductive glass (glass coated with $\mathrm{ITO}, \mathrm{In}_{2} \mathrm{O}_{3}: \mathrm{Sn}$ ), with an area of $0.5 \mathrm{~cm}^{2}$, which is used as a working electrode, placed parallel to the optical path of the cell. A reversible hydrogen electrode is used as the reference electrode, which is located close to the upper surface of the conductive glass, leaving the optical path of the cell free. The electrosynthesis were performed by potentiodynamic scans (30 successive cycles by cyclic voltammetry, CV) between 0.05 and $1.00 \mathrm{~V}$, at a potential scan, $v$, of $20 \mathrm{mV} \mathrm{s}^{-1}$.

The electropolymerization and electrochemical analysis were carried out from a solution, previously bubbled with $\mathrm{N}_{2}$, of $\mathrm{H}_{2} \mathrm{SO}_{4} 1.0 \mathrm{~mol} \mathrm{~L}^{-1}$, using an Autolab PGSTAT-20 potentiostat controlled by a GPES 4.3 software. Spectra in the UVVis region for in-situ monitoring and deposit characterization were recorded in a UV-Vis Shimadzu spectrophotometer model Multispec-1501 with diode array, controlled by the Hardlock software, scanning from smaller to longer wavelength.

Finally, the images by SEM were obtained in a scanning electron microscope ZEISS LEICA model DSM 440, for which the samples were coated with a nanometric layer of gold, by means of sputtering, to provide an adequate conductivity for the analysis.

\section{RESULTS AND DISCUSSION}

Figure 1 shows the cyclic voltammograms recorded during electropolymerization from solutions of the monomers ANI and OMA in different molar ratios, observing a peak designated as A/A' corresponding to the transition from leucoemeraldine to emeraldine [17-21]. In addition, the polymers obtained in the presence of $o$-methoxyaniline present a third process, $\mathrm{B} / \mathrm{B}^{\prime}$, assigned to the degradation of the polymer [17, 22].

At first, it can be seen the intermediate voltammetric properties between homopolymers and copolymers. Further, it is important to note that during the 
electropolymerization of ANI on ITO the development of the B/B 'process, described in the literature, is not clearly observed, which would indicate that in this case no secondary species and/or degradation of the polymer would be generated. However, the deconvolution of the last voltammetric cycle (Figure 2) does account for a small contribution of this process to current density, but associated with the $\mathrm{C} / \mathrm{C}$ 'process, which increases with the increase in concentration, causing loss the resolution required to observe the $\mathrm{B} / \mathrm{B}$ 'process.
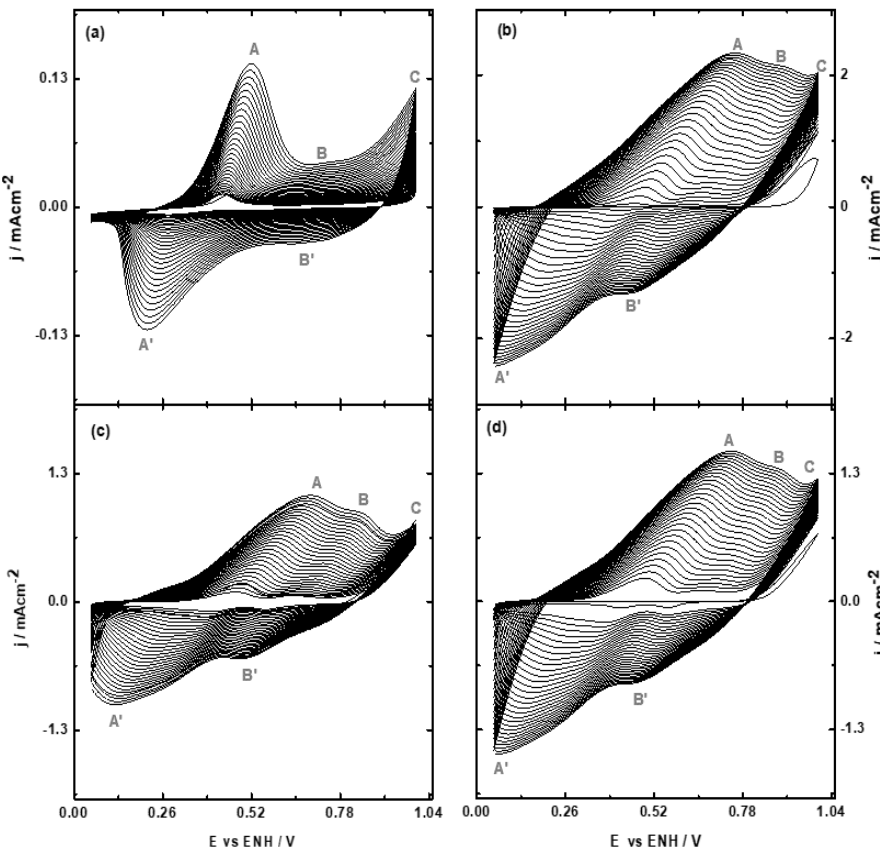

Figure 1. CV profiles during the electropolymerization on ITO, from solutions

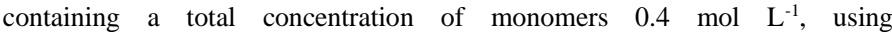
aniline:methoxyaniline a) 1:0; b) 0:1; c) 3:1 and d) $1: 3$ ratios in $1.0 \mathrm{~mol} \mathrm{~L}^{-1} \mathrm{H}_{2} \mathrm{SO}_{4}$ at $v=20 \mathrm{mV} \mathrm{s}^{-1}$ [ $v$ selected from ref. 17].

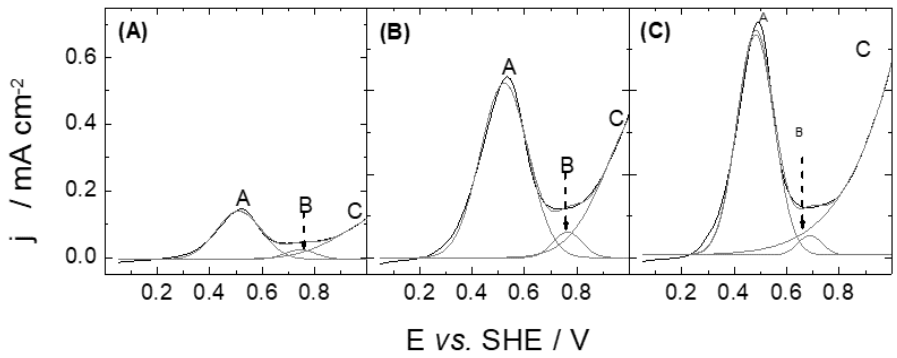

Figure 2. Deconvolution (Origin Pro 8.0) of the last voltammetric oxidation cycle during ANI electropolymerization from: A) 0.1 ; B) 0.25 , and C) $0.4 \mathrm{~mol} \mathrm{~L}^{-1} \mathrm{ANI}$ in $1.0 \mathrm{~mol} \mathrm{~L}^{-1} \mathrm{H}_{2} \mathrm{SO}_{4} \cdot v=20 \mathrm{mV} \mathrm{s}^{-1}$.

In Figure 3 the graph corresponding to the quotient $I_{b} / I_{a}$ is presented as a function of the number of voltammetric cycles during the growth of POMA for different concentrations. This shows that the concentration of $o$-methoxyaniline is inversely proportional to the formation of side-products during growth in the first cycles, there being a preference for the formation of compounds such as $\mathrm{N}$ phenyl-1,4-benzoquinonadiimine (PBQ) [23] above the growth of the deposit. This can be attributed to the electron donor nature of the methoxy group, which would favor the reactivity of the radical [24], increasing the possibility of parallel reactions [15]. In this way, by increasing the molar ratio of OMA, in the growth of the copolymers a higher current density is observed for the degradation process. However, the current density observed in the first oxidation peak (A/A') is much greater than that presented by the electropolymerization of PANI at the same number of cycles, but at the same time, less than that presented by poly-omethoxyaniline, corroborating that the reactivity is increased by the presence of the methoxy group, which is consistent, on the one hand, with the electron donor nature promoted by the methoxy group, which favors reactivity [24] and increases the possibility of parallel reactions.

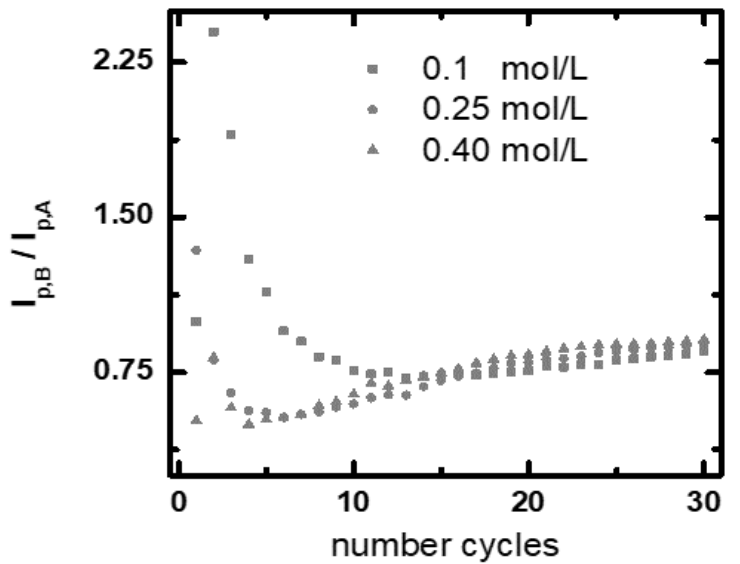

Figure 3. Graph of $I_{p B} / I_{p A}$ as a function of the number of cycles during the electropolymerization of OMA on ITO, from: (---) $0.1 \mathrm{~mol} \mathrm{~L}^{-1},(--)$ $0.25 \mathrm{~mol} \mathrm{~L}^{-1}$, and (--) $0.4 \mathrm{~mol} \mathrm{~L}^{-1}$ monomer in $1.0 \mathrm{~mol} \mathrm{~L}^{-1} \mathrm{H}_{2} \mathrm{SO}_{4}$, at $v=20 \mathrm{mV} \mathrm{s}^{-1}$.

Figure 4 shows that during the last cycle of electropolymerization of ANI there is a strong absorbance close to $425 \mathrm{~nm}$, corresponding to the first stage of monomer oxidation [25] -radical formation (1)- and agrees with the observed potential of $0.439 \mathrm{~V}$. Meanwhile, the formation of bi-polaron (2) is observed at $800 \mathrm{~nm}$, as it has been described in the literature, which corresponds to one of the most characteristic of conducting polymers based on aniline [17, 25]. The $\pi$ $\pi^{*}$ interaction of the benzoic rings (3), corresponding to the PANI leucoemeraldin conformation, is also seen [25]. This interaction has its maximum close to $305 \mathrm{~nm}$ and is consistent with the applied potential of $0.05 \mathrm{~V}$. It is important to point out that the spectro-cyclovoltammograms corresponding to the electropolymerization of ANI maintain the same profile in the different cycles analyzed $(n=1,5,10,15,20,25,30)$, increasing only the intensity of the absorbance in each one of them.

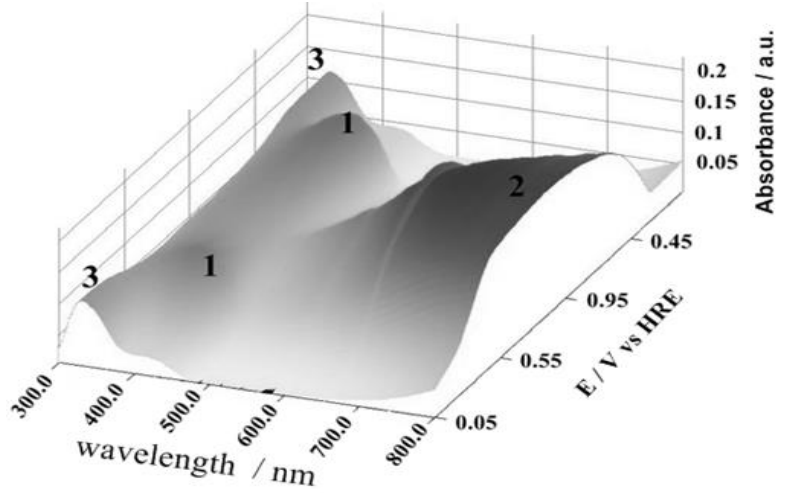

Figure 4. Uv-Visible spectro-cyclovoltammogram for cycle 30 during the electropolymerization of ANI on ITO, from $0.4 \mathrm{~mol} \mathrm{~L}^{-1}$ aniline in $1.0 \mathrm{~mol} \mathrm{~L}^{-1}$ $\mathrm{H}_{2} \mathrm{SO}_{4}$, at $v=20 \mathrm{mV} \mathrm{s}^{-1}$.

In the case of OMA, however, during the first cycles (Figure 5A) the behavior is totally different, especially in the formation of radicals (1), which is only observed when scanning in the negative direction, giving an account of low or almost no oxidation of the monomer in the anodic sense. In addition, the peaks corresponding to the formation of bi-polaron (2) and the interaction $\pi-\pi^{*}$ of the benzoic rings (3) show a proportionally low intensity between them compared to that presented by PANI. Near $560 \mathrm{~nm}$, a new absorption band is distinguished, (4), described in the literature as oligomer formation [26], with oxazine structures, which are part of the chain and are occluded within the polymer matrix [27]. This is better distinguished in the top view of the first spectrocyclovoltammogram (Figure 5B). In this way, the potentials associated with the oxidations of $\mathrm{A} / \mathrm{A}^{\prime}, \mathrm{C} / \mathrm{C}^{\prime}$, and $\mathrm{B} / \mathrm{B}^{\prime}$ processes move towards more positive values, the result of a decrease in the conductivity of the deposit [6]. Also, the redox pair is much less reversible, as noted by Buron et al. in the potentiostatic synthesis on different types of conductive glass [6]. 

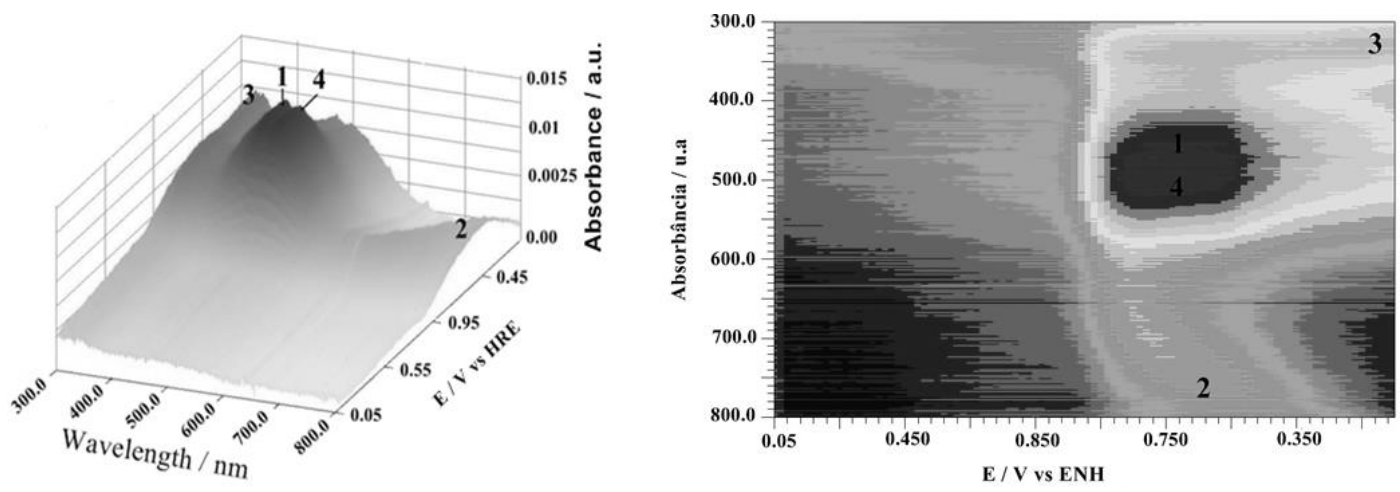

Figure 5. (A) Uv-Visible spectro-cyclovoltammogram of the first cycle during the electropolymerization of OMA on ITO, from 0.4 mol $\mathrm{L}^{-1} o$-methoxyaniline in $1.0 \mathrm{~mol} \mathrm{~L}^{-1} \mathrm{H}_{2} \mathrm{SO}_{4} ; v=20 \mathrm{mV} \mathrm{s}^{-1}$. (B) Top view of Fig. 5A.

In the spectro-cyclovoltammograms of the growth of the copolymers from different ratios ANI:OMA, the influence of $o$-methoxy on the reactivity of the monomer and on the generation of oligomers is observed. In the first cycle, for the ratio 3:1 (Figure 6), it is possible to observe the formation of radicals, both when scanning in a positive and negative direction. The formation of oligomers is also observed, due to the presence of $o$-methoxyaniline. On the other hand, in the spectro-cyclovoltammograms of the growth of the copolymers registered for the molar ratio 1:3, a strong formation of oligomers is noteworthy, attributable to the high concentration of $o$-methoxyaniline. Thus, in both spectrocyclovoltammograms there are analogous behaviors, but it is important to note that the reactivity and the reaction velocity is greater for polymers and copolymers grown from $o$-methoxyaniline.

In Figure 7-I are shown the UV-vis spectra of electrolytic solutions after electropolymerization. A significant absorbance close to $560 \mathrm{~nm}$ is observed when working in the presence of $o$-methoxyaniline, which is not distinguished for the solutions used for the growth of polyaniline. In literature this maximum is attributed to the formation of diphenyl benzidine and $\mathrm{N}$ ', $\mathrm{N}$-diphenylbenzidine, in the form of cationic radical oligomers and dicationic radical, respectively [14], whose formation would be favored depending on the concentration of monomer.

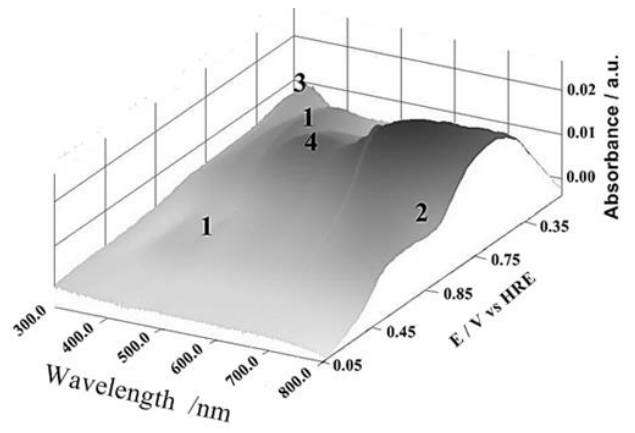

Figure 6. UV-visible spectro-cyclovoltammograms during cycle 30 of electrocopolymerization on ITO, from a molar ratio ANI:OMA $=3: 1+1.0 \mathrm{~mol}$ $\mathrm{L}^{-1}$ of $\mathrm{H}_{2} \mathrm{SO}_{4} ; v=20 \mathrm{mV} \mathrm{s}^{-1}$.

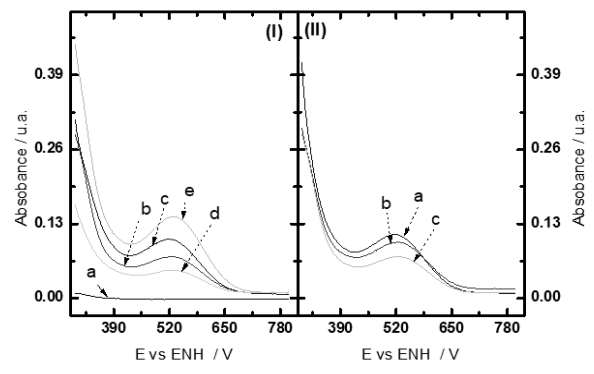

Figure 7. Uv-Visible spectra of the resulting solutions after electropolymerizations performed from different proportions ANI:OMA, (I): (a) $1: 0$; (b) $0: 1$; (c) $3: 1$; (d) $1: 1$; (e) $1: 3$, and from different concentrations of POMA, (II): (a) 0.1 ; (b) 0.25 , and (c) $0.4 \mathrm{~mol} \mathrm{~L}^{-1}$.
In Figure 7-II, it is observed that the increase of o-methoxyaniline concentration is inversely proportional to the formation of oligomers. This generation of oligomers has been described by del Valle et al. [28], as the first stage during the electrosynthesis of poly-o-phenylenediamine, constituting a high density of this type of structure in the interface, to subsequently originate the nuclei that will give rise to the growth of the polymeric deposit, when the oligomers reach a long chain that makes them insoluble and precipitates on the electrode.

In the case of POMA electrosynthesis, although the oligomers are generated rapidly, they are more soluble or have a shorter chain length, because a large amount is clearly observed at the interface and they do not generate the nucleation and growth process on the surface of the electrode, increasing the concentration of $o$-methoxyaniline in solution.

Figure 8 shows cyclic voltammograms corresponding to the responses of the electrogenerated deposits in solution that only contains the supporting electrolyte (1.0 $\left.\mathrm{mol} \mathrm{L}^{-1} \mathrm{H}_{2} \mathrm{SO}_{4}\right)$. In the profile corresponding to the PANI-modified electrode (Figure 8a), the interconversion of leucoemeraldin to emeraldine (A/A') and from emeraldine to pernigraniline $\left(\mathrm{B} / \mathrm{B}^{\prime}\right)$ is clearly distinguished. In contrast, for the films grown from $o$-methoxyaniline solutions of different concentrations (Figures $8 \mathrm{~b}, \mathrm{c}, \mathrm{d}$, and e), the degradation process of the polymer is observed. One of the main characteristics of these voltammetric profiles is the displacement of the first oxidation potential towards more positive values, which can be attributed to the methoxy group which, as mentioned, favors the faster formation of oligomers.

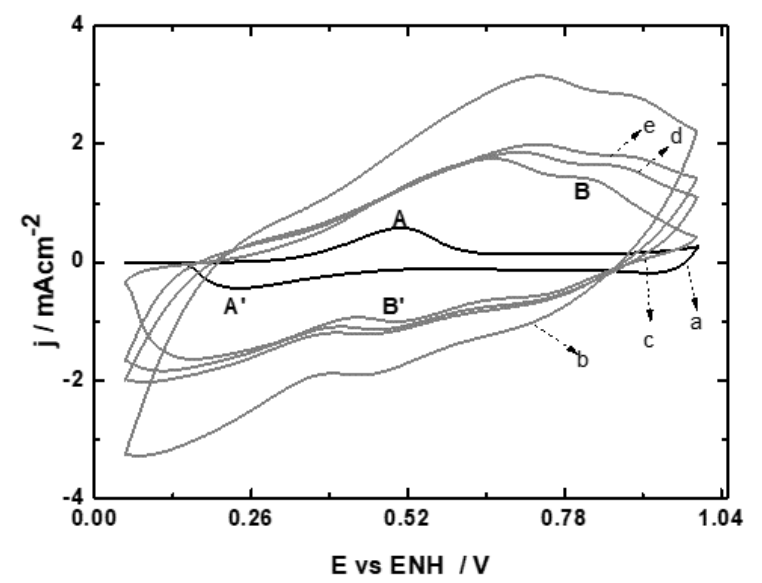

Figure 8. Voltammetric responses in $\mathrm{H}_{2} \mathrm{SO}_{4} 1.0 \mathrm{~mol} \mathrm{~L}^{-1}$ at $20 \mathrm{mV} \mathrm{s}^{-1}$ of deposits prepared from: (a) ANI; (b) $o$-methoxyaniline; Ani:OMA in proportion (c) $3: 1 ;$ (d) $1: 1$, and (e) $1: 3$.

In Figure 9, UV-vis spectra of the polymer deposits obtained by cyclic voltammetry are presented. It can be seen two typical signals of aniline-based polymers, one that corresponds to the formation of the bi-polaron $(800 \mathrm{~nm})$ taking into account the conductive property of the polymer- and another, close to $425 \mathrm{~nm}$, associated with the radicals that are found in the polymer matrix [25]. 


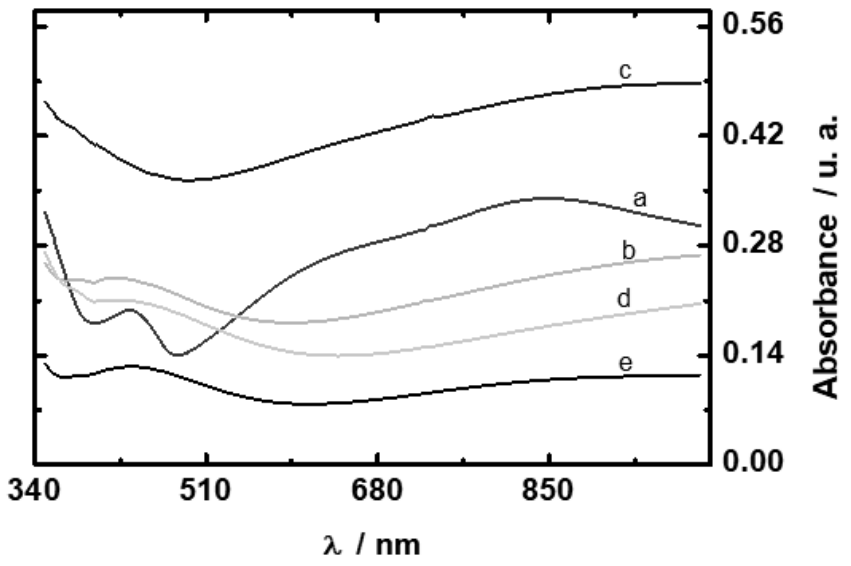

Figure 9. Uv-Visible spectra of the electropolymerized deposits on ITO: (a) PANI; (b) POMA, and copolymers: PANI:OMA prepared from the ratios (c) 3:1; (d) $1: 1$, and (e) 1:3.

In the case of copolymers it is possible to observe that poly(aniline-co-omethoxyaniline) grown from a 3:1 molar ratio has a higher band intensity in the low energy region of the spectrum, indicating an increase in mobility electronic, due to greater presence of aniline.

On the other hand, both from the spectro-voltammograms of POMA and copolymers growth, and the spectra in the UV-vis region of the solutions after the synthesis, bands of the oligomers are not observed, indicating that most of these structures remain in solution and only a small portion of the OMA oligomers are found in the polymer matrix, which is sufficient to produce the displacement of the first oxidation potential towards more positive values, as was observed in the electrochemical profiles, and for generate a change in the type of nucleation and growth of the respective deposits, with the consequent effect on the conductivity of the electrode modified with the respective polymer. The latter is corroborated through morphological analysis.

Figure 10 shows the SEM images of the polymers grown on ITO by CV, which account for the formation of nuclei that grow to give origin to the deposit whose morphology is determined precisely by the type of nucleus and its shape and speed of growth.

PANI (Figure 10a) presents a hemispheric-like granular morphology of sizes close to nanometers, which is generated by small hydrophobic nuclei absorbed on the surface of the electrode [26]. On the other hand, the deposits of poly-omethoxyaniline (Fig. 11b), present a homogeneous, plate-like surface with some conglomerates on the surface, which is mainly associated with the type of counter-ion $\mathrm{SO}_{4}{ }^{2-}$, coming from the acid contained in the electrolytic solution used in electrosynthesis [22].

Finally, Figure $10 \mathrm{c}$ shows the morphology of poly(aniline-co-omethoxyaniline) grown on ITO from a 1:1 molar ratio of monomers. This resembles that of the poly-o-methoxyaniline homopolymer, which is consistent with the high reactivity that the methoxy substituent generates, as has been verified here. This type of morphology is also observed for all the proportions used in this study, indicating that for any concentration of $o$-methoxyaniline the morphology is directly affected -the POMA morphology predominates-, and with it, the conductivity.
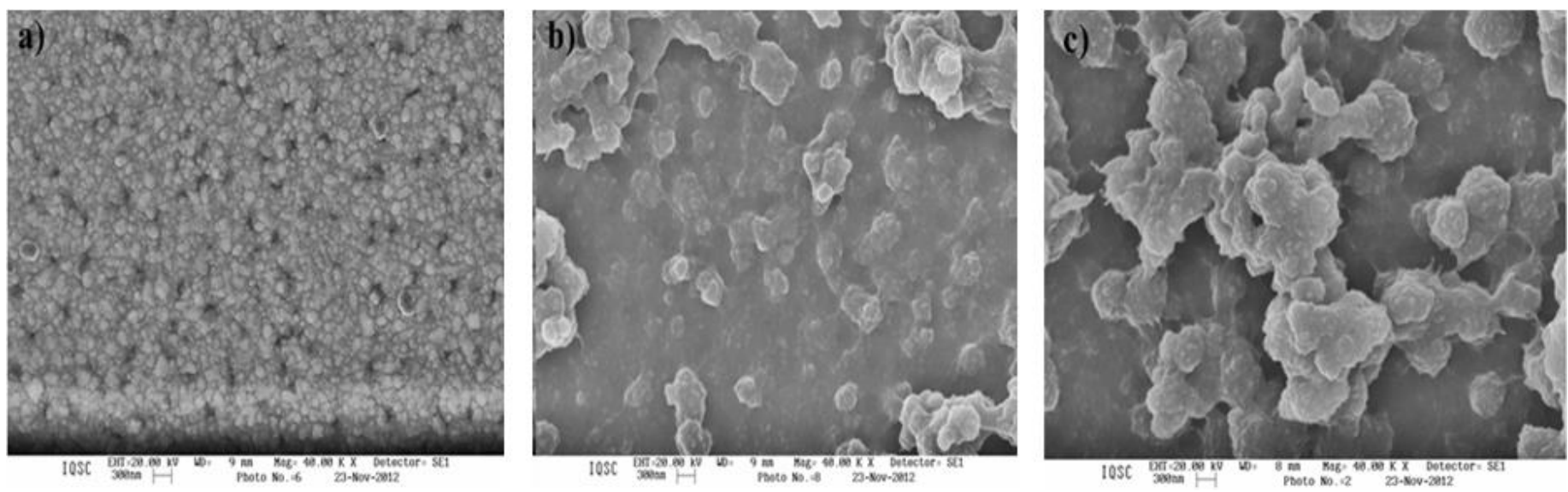

Figure 10. SEM micrographs of the deposits obtained by cyclic voltammetry at $v=20 \mathrm{mV} \mathrm{s}^{-1}$ on ITO, from molar ratios of ANI:OMA; (a) 1:0; (b) 0:1; and (c) $1: 1$ in $1.0 \mathrm{~mol} \mathrm{~L}^{-1} \mathrm{H}_{2} \mathrm{SO}_{4}$

\section{CONCLUSIONS}

The UV-vis monitoring in-situ during the electrosynthesis of poly(aniline-co$o$-methoxyaniline) corroborated a strong formation of oligomers attributable to the methoxy group in the ortho position, which gives a much higher reactivity to the monomer.

It is verified that the intermediate voltammetric and spectroscopic properties between homopolymers and copolymers.

The methoxy group promotes a greater growth of poly-o-methoxyaniline, than that shown by polyaniline at the same times and experimental conditions. Despite this interesting reactivity, an important problem occurs, such as the decrease in the conductivity of the $\mathrm{CP}$, attributable to the variation of the deposit morphology. In any case, this copolymer could be tested as a corrosion protector, for which it could be better than the respective homopolymers.

\section{ACKNOWLEDGEMENTS}

The authors acknowledge the financial support of Universidad Mayor I2018022 and National Council for Scientific and Technological Development (CNPq), Brazil.

\section{REFERENCES}

1. P. Sbaite, D. Huerta-Vilca, C. Barbero, M. C. Miras, A. Motheo, Eur. Polym J. 40(7), 1445 (2004).

2. D. Sazou, M. Kourouzidou, E. Pavlidou, Electrochim. Acta 52(13), 4385 (2007).

3. A. J. Dominis, G. M. Spinks, G. G. Wallace, Prog. Org. Coat. 48(1), 43 (2003).

4. J. R. Santos, L. H. C. Mattoso, A. Motheo, Electrochim. Acta 43(3), 309 (1998).

5. M. F. Pantoja, "Sínteses Eletroquímica e caracterizações de polímeros provenientes de misturas de anilina e o-metoxi-anilina", Mestrado em Físico-Química -Instituto de Química de São Carlos, Universidade de São Paulo, São Carlos, 1998.

6. C. C. Buron, B. Lakard, A. F. Monnin, V. Moutarlier, S. Lakard, Synth. Met 161(19-20), 2162 (2011).

7. U. Leon-Silva, M. E. Nicho, H. L. Hu, R. Cruz-Silva, Sol. Energ. Mat. Sol. C., 91(15-16), 1444 (2007).

8. D. D. Borole, U. R. Kadapi, P. P. Mahulikar, D. G. Hundiwale, Polym.-Plast. Techn. Eng., 47(7), 643 (2008).

9. S. M. Ghoreishi, M. Shabani-Nooshabadi, M. Behpour, Y. Jafari, Prog. Org Coat., 74(3), 502 (2012) 
10. A. T. Ozyilmaz, N. Colak, G. Ozyilmaz, A. K. Sangun, Prog. Org. Coat., 60(1), 24 (2007).

11. H. Bejbouji, L. Vignau, J. L. Miane, M. T. Dang, E. Oualim, M. Harmouchi, A. Mouhsen, Sol. Energ. Mat. Sol. C., 94(2), 176 (2010).

12. S. Saravanan, M. R. Anantharaman, S. Venkatachalam, D. K. Avasthi, Vacuum, 82(1), 56 (2007).

13. V. Bavastrello, T. B. C. Terencio, C. Nicolini, Polym., 52(1), 46 (2011).

14. B. H. Lei Zhang, L. Qiuhua, Amer. J. Anal. Chem., 2, 182 (2011).

15. A. F. Viva, E. M. Andrade, F. V. Molina, M. I. Florit, J. Electroanal. Chem., 471(2), 180 (1999).

16. A. Zimmermann, U. Kunzelmann, L. Dunsch, Synth. Met., 93(1), 17 (1998).

17. A. J. Motheo, M. F. Pantoja, E. C. Venancio, Sol. St. Ion., 171(1-2), 91 (2004).

18. S. Y. Cui, S. M. Park, Synth. Met., 105(2), 91 (1999).

19. P. C. Rodrigues, M. P. Cantao, P. Janissek, P. C. N. Scarpa, A. L. Mathias, L. P. Ramos, M. A. B. Gomes, Eur. Polym. J., 38(11), 2213 (2002).
20. Y. Guo, J. Xu, "Electrochemical Polymerization and Electric Property of Polyaniline", in: International Conference on Information Science and Technology, Nanjing, Jiangsu, China, pp. 1244 - 1247 (2011).

21. K. Darowicki, J. Kawula, Electrochim. Acta, 49(27), 4829 (2004).

22. S. Patil, M. A. More, P. P. Patil, J. Appl. Polym. Sci., 74(13), 3009 (1999).

23. M. Matsushita, H. Kuramitz, S. Tanaka, Environm. Sci. Tech., 39(10), 3805 (2005).

24. M. C. Bernanrd, A. H. L. Goff, H. Arkoub, B. Saidini, Electrochim. Acta, 52(15), 5030 (2007).

25. A. U. H. Ali Shah, R. Holze, Synth. Met., 156(7-8), 566 (2006).

26. J. Stejskal, I. Sapurina, M. Trchova, Prog. Polym. Sci., 35(12), 1420 (2010).

27. J. Widera, W. Grochala, K. Jackowska, J. Bukowska, Synth. Met., 89(1), 29 (1997).

28. M. A. del Valle, F. R. Diaz, M. E. Bodini, G. Alfonso, G. M. Soto, E. D. Borrego, Polym. Int., 54(3), 526 (2005). 